\title{
Generalized pulmonary hyperinflation and Fallot's tetralogy in a neonate investigated by pulmonary physiological and radioisotopic methods
}

\author{
S. G O D F R EY, R. R O NCHETTI ${ }^{1}$, JANET S T OCKS, \\ a n d K A THER INE HALLIDIE-SMITH
}

Department of Paediatrics and Neonatal Medicine, Institute of Child Health, and Division of Cardiovascular Disease, Department of Medicine, Hammersmith Hospital, London W12 OHS

\begin{abstract}
Godfrey, S., Ronchetti, R., Stocks, Janet, and Hallidie-Smith, Katherine (1975). Thorax, 30, 452-460. Generalized pulmonary hyperinflation and Fallot's tetralogy in a neonate investigated by pulmonary physiological and radioisotopic methods. An infant is described who presented a complex cardiopulmonary problem which was evaluated with the help of new physiological techniques. The infant was born at term after an emergency Caesarian section for fetal distress and was found to have meconium aspiration. He remained persistently tachypnoeic and hypoxic despite high ambient oxygen. Chest radiographs suggested cystic lesions at the lung bases, and lung function tests confirmed hyperinflation with delayed nitrogen washout. In addition the child had signs of Fallot's tetralogy, and this diagnosis was confirmed by cardiac catheterization. Because of persistent hypoxia and tachypnoea disproportionate to the cardiac condition, the possibility of localized lung disease was considered. Regional lung function tests were carried out in the neonatal period and again at six months of age using radioisotopic ${ }^{13} \mathrm{~N}$ given by both inhalation and injection. These studies showed gross ventilation/perfusion imbalance in the lungs, particularly marked at the bases, but with enough generalized abnormality to preclude the possibility of surgical intervention. The principles of the measurement of lung mechanics in the newborn by whole-body plethysmography, nitrogen washout, and regional radioisotopic spirometry are outlined. The pariicular value of these techniques in the evaluation of complex disorders is discussed, especially where both cardiac and pulmonary abnormalities are present.
\end{abstract}

The diagnosis of lung disease in a baby with congenital heart disease or vice-versa can be very difficult (Roberton, Hallidie-Smith, and Davis, 1967) and taxes the skill of the clinician. Tachypnoea, hypoxia, and heart failure are common in either condition. There is also an association between congenital lobar emphysema and congenital heart disease (Lincoln et al., 1971) which further increases the difficulty of distinguishing the major disorder when pulmonary hyperinflation is present. The investigation of pulmonary function may throw some light on the problem since pulmonary compliance has been shown to be abnormal in some infants with congenital heart disease, while their lung volume

1Present address: Department of Paediatrics, University of Parma, Italy and airways resistance usually remain normal (Howlett, 1972) whereas lung disease in infancy음 usually affects lung volume and resistance as well. $\supset$

We recently had cause to investigate an infant with a complex cardiopulmonary problem, largely N as a result of which we developed new techniques for the detailed assessment of lung mechanics and $N$ regional lung function to help elucidate the problem. The case report is presented first, ando some details of the techniques are given in thee appendix.

\section{CASE REPORT}

The patient was a male infant, born at term in this hospital on 5 January 1974, weighing $2880 \mathrm{~g} \stackrel{\mathbb{Q}}{\mathbb{Q}}$ (10th/25th percentile) to a primaparous Indian 
mother, who had had an uneventful pregnancy. She was admitted to the obstetric unit in established labour, with meconium staining of the liquor. The fetal heart rate fell to 108 beats per minute and an emergency Caesarian section was performed under general anaesthesia. The baby cried immediately after birth but was very tachypnoeic, and crepitations were heard over both lungs. Inspection showed meconium in the larynx and trachea, which was aspirated under direct vision, but the tachypnoea persisted and the infant was transferred to the neonatal intensive care unit. A chest radiograph at this time showed widespread patchy changes consistent with meconium aspiration. The respiratory rate was 100 to 120 breaths per minute, the infant became cyanosed when disturbed, and there were crepitations in the lungs, but no other abnormalities were detected. At the age of 12 hours, radial arterial blood gases showed $\mathrm{Po}_{2} 41 \mathrm{mmHg}$, $\mathrm{PCO}_{2} 42 \mathrm{mmHg}$, and $\mathrm{pH} \mathrm{7 \cdot 40.} \mathrm{An} \mathrm{umbilical} \mathrm{artery}$ catheter was inserted and the baby was nursed in $25 \%$ oxygen without an obvious change in colour. Antibiotics were given because of the possibility of infection.

The infant remained tachypnoeic during the next four days; his arterial $\mathrm{Po}_{2}$ varied from 40 to
$50 \mathrm{mmHg}$ in air and was little influenced by increasing concentrations of ambient oxygen up to $50 \%$. There was an initial rapid weight gain of $250 \mathrm{~g}$ in the first five days, accompanied by some slight hepatomegaly and oedema of the feet. A systolic murmur was heard at the left sternal edge. The electrocardiogram showed right axis deviation and right ventricular hypertrophy: his chest radiograph showed cardiac enlargement and an increase in the lung volume with some cyst-like areas, especially at the bases. These changes became more marked later on and are shown in Figure 1. Haematological and biochemical investigations were normal.

The possibility of heart failure due to lung disease or combined heart and lung disease was considered, and pulmonary function studies were carried out in the whole-body infant plethysmograph, as described in Appendix 1. These were repeated at intervals over the next three weeks. The results are given in Table $I$, together with the expected values derived from studies in this laboratory and elsewhere. There was gross tachypnoea, with a small tidal volume, and hyperinflation with an approximate doubling of the thoracic gas volume. Airways resistance was relatively normal for the baby's size, although it was raised in

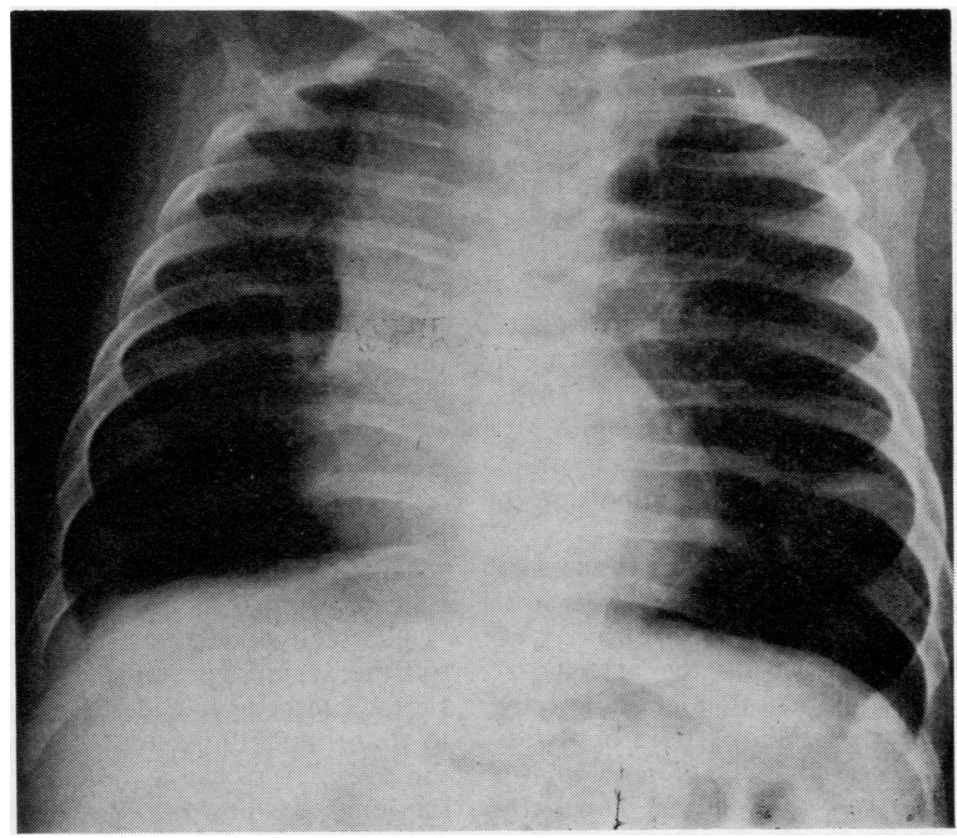

FIG. 1. Chest radiograph taken at the age of 6 months showing hyperinflation with areas of increased transradiancy, especially at the bases. 
T A B L E I

RESULTS OF PULMONARY FUNCTION TESTS

\begin{tabular}{|c|c|c|c|c|c|c|c|c|c|}
\hline & \multicolumn{5}{|c|}{ Age } & \multirow{2}{*}{$\begin{array}{c}\text { Expected } \\
\text { Values } \\
\text { during } \\
\text { Neonatal } \\
\text { Period }^{1}\end{array}$} & \multirow{2}{*}{ 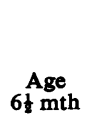 } & \multirow{2}{*}{$\begin{array}{l}\text { Expected } \\
\text { Values for } \\
5.6 \mathrm{~kg} \\
\text { Infant }\end{array}$} & \multirow[b]{2}{*}{ References } \\
\hline & 6 days & 10 days & 13 days & 17 days & 26 days & & & & \\
\hline $\begin{array}{l}\text { Tidal volume (ml) } \\
\text { Frequency/minute } \\
\text { Minute ventilation }(\mathrm{ml} / \mathrm{min}) \\
\text { Thoracic gas volume }(\mathrm{ml}) \\
\text { Functional residual capacity }(\mathrm{ml}) \\
\text { (a) at } 3 \text { minutes } \\
\text { (b) extrapolated } \\
\text { Dynamic compliance }\left(\mathrm{ml} / \mathrm{cmH}_{2} \mathrm{O}\right) \\
\text { Airway resistance }\left(\mathrm{cmH}_{2} \mathrm{O} / \mathrm{l} / \mathrm{per} \mathrm{sec}\right)\end{array}$ & $\begin{array}{r}7 \cdot 0 \\
165 \\
1155 \\
203\end{array}$ & $\begin{array}{c}7 \cdot 5 \\
168 \\
1260 \\
250\end{array}$ & $\begin{array}{c}7 \cdot 5 \\
170 \\
1270 \\
270 \\
138 \\
237 \\
1 \cdot 9 \\
26 \cdot 5\end{array}$ & $\begin{array}{c}8 \cdot 0 \\
96 \\
768 \\
248\end{array}$ & $\begin{array}{c}10 \cdot 9 \\
73 \\
795 \\
230\end{array}$ & $\begin{array}{l}19 \cdot 0 \\
35 \\
665 \\
93 \\
90 \\
90 \\
5 \cdot 8 \\
35 \cdot 0\end{array}$ & $\begin{array}{c}40 \cdot 0 \\
77 \\
3080 \\
368 \\
- \\
11 \cdot 5 \\
26 \cdot 0\end{array}$ & $\begin{array}{c}34 \cdot 0 \\
30 \\
1020 \\
198 \\
- \\
20 \cdot 0 \\
10 \cdot 0\end{array}$ & $\begin{array}{l}\text { A,B,C,D,E } \\
\mathbf{A}, \mathbf{B}, \mathbf{C}, \mathbf{F} \\
\mathbf{A}, \mathbf{B}, \mathbf{C}, \mathbf{F} \\
\mathbf{G}, \mathbf{H}, \mathbf{I}, \mathbf{J}, \mathbf{K} \\
\mathbf{L}, \mathbf{M} \\
\mathbf{B}, \mathbf{E}, \mathbf{F}, \mathbf{G}, \mathbf{J} \\
\mathbf{N}\end{array}$ \\
\hline
\end{tabular}

The expected values are derived from the weighted means of published data on normal infants of approximately the same weight. ${ }^{2}$ Measured two days after cardiac catheterization.

A Measured two days after car
A Swys (1949)
C Strang (1961)
D Nelson et al. (1962)
E Drorbaugh et al. (1963)

F Cook et al. (1957)
G Chu et al. (1964)
H Lacourt and Polgar (1974)
I Phelan and Williams (1969)
J Polgar and String (1966)

relation to lung volume, while dynamic compliance was low; however, this latter result is difficult to interpret in the presence of such gross tachypnoea. Functional residual capacity after a three-minute period of rebreathing (measured by a rebreathing technique as described in Appendix 2) was considerably less than that of the thoracic gas volume measured by the plethysmograph, indicating the presence of trapped gas, and the rate of nitrogen washout was inordinately slow (Fig. 2), indicating poor ventilation. When the nitrogen washout curve was extrapolated to give the theoretical concentration at equilibrium, the calculated functional residual capacity was then very similar to the measured thoracic gas volume (Table I).

The infant was treated with digoxin and diuretics, and his heart failure improved, but the tachypnoea and hypoxia persisted. The calculated venous admixture breathing air was $50 \%$, and even when the infant was given $100 \%$ oxygen, the arterial $\mathrm{PO}_{2}$ rose only to $117 \mathrm{mmHg}$, indicating a residual right-to-left shunt of $24 \%$. These results suggested that approximately half the venous admixture was due to an imbalance of ventilation and perfusion in the lungs, the rest being due to anatomical shunting.

By this stage it was clear that the infant had both abnormal lungs and congenital heart disease, and a clinical diagnosis was made of tetralogy of Fallot with a possible patent ductus arteriosus. Cardiac catheterization and angiocardiography confirmed the presence of Fallot's tetralogy with a marked bronchial arterial blood supply to the lungs, but the ductus was not patent. The baby made good progress over the next two weeks, with a normal weight gain, but remained tachy-
K Klaus et al. (1962)

L Geubelle et al. (1959)

M Nelson et al. (1963)

N Radford (1974)

FIG. 2. Nitrogen washout curves on patient and two control infants of similar size. The proportion of nitrogen remaining in the lungs which could bes excreted until rebreathing equilibrium was obtained has been plotted against time on a semilogarithmic. graph.

pnoeic, and his chest radiograph still showed per: sistent hyperinflation, which was confirmed bye repeated lung function studies.

The tachypnoea was felt to be disproportionates to the relatively mild and well-compensateco Fallot's tetralogy, and it was therefore important? to determine the extent of the lung disease. Ato the age of 5 weeks a radioisotope examination of the lungs was performed with ${ }^{13} \mathrm{~N}$ using the gammæ camera as detailed in Appendix 3. The most ob $\frac{1}{2}$ vious finding was that the area of radioactivityo 
after injection of the isotope was much larger than after inhalation, especially at the bases, showing the presence of large, poorly ventilated but perfused regions. The inhalation curve was of poor quality, but calculation of regional ventilation from the washout of injected activity showed generalized underventilation in relation to regional volume. It was concluded that the infant had generalized pulmonary disease with gas trapping and poor ventilation, and that the changes were probably more marked at the bases. His $\alpha_{1}-$ antitrypsin level was normal. Surgery was not considered possible in the light of the combined heart and generalized lung disease.

The baby was discharged on a maintenance dose of digoxin and was followed up in the clinic. $\mathrm{He}$ grew along the 3 rd percentile and reached his milestones at appropriate times. However, he remained tachypnoeic with respiratory rates consistently recorded in the region of 80 breaths per minute. At the age of 6 months he was re-investigated. Lung function studies (Table I) showed persistent hyperinflation of the lungs, with a raised airway resistance and low compliance, indicating generalized lung abnormality. The chest radiograph (Fig. 1) showed progression of the lung disease with obvious basal radiolucencies. A repeat ${ }^{13} \mathrm{~N}$ study was carried out using an improved bolus technique and gave much clearer results, though essentially confirming the earlier findings. The whole lung activity was greater after infusion than after inhalation and the wash-out after infusion was much slower than after inhalation because the trapped gas was very slowly ventilated (Fig. 3). From these studies it was possible to calculate indices of regional ventilation and perfusion (Table II) which showed generalized poor function, most severe in the bases. The abnormalities appeared to be worse than in the previous study.

The baby is still being followed at the time of writing. Diagnostic lung biopsy is not thought to be justified as the condition is clearly not amenable to surgical or medical correction.

\section{DISCUSSION}

The initial course of this infant's disease suggested birth asphyxia followed by meconium aspiration. The evolution of the chest radiograph and the persisting abnormalities then suggested a possible diagnosis of congenital cystic adenomatoid malformation, especially since this has been described fairly frequently in association with oedema (Merenstein, 1969). The development of heart

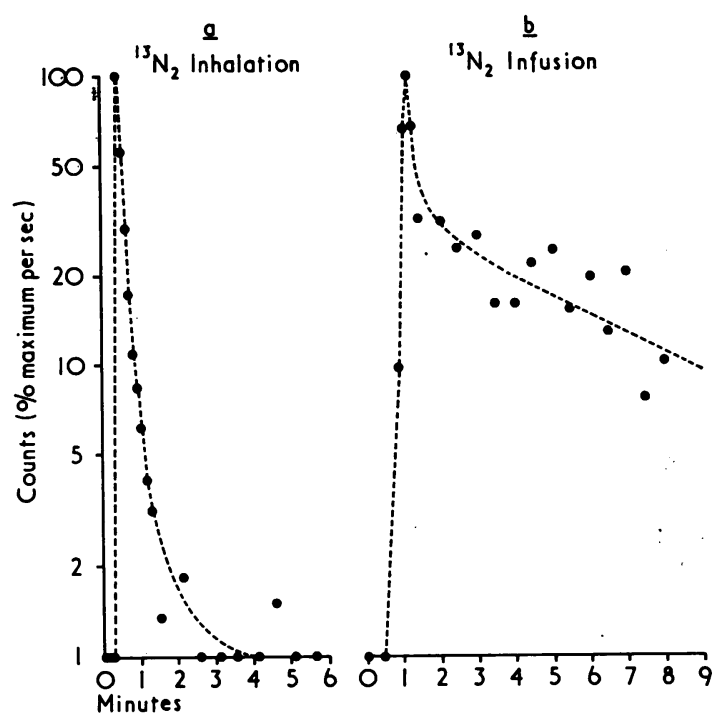

FIG. 3. Whole lung washout curves for radioactivity after (a) inhalation of ${ }^{13} N_{2}$ and (b) injection of ${ }^{13} N_{2}$. The counts have been expressed on a logarithmic scale as percentage of maximum. The very slow washout of radioactivity from perfused lung can be seen which indicates gross mismatching of ventilation and perfusion in the lungs. The regional variation in washout is given in Table II.

T A B L E I I

REGIONAL LUNG FUNCTION AT 6 MONTHS OF AGE (A) Distribution Indices (normal $=1 \cdot 0$ )

\begin{tabular}{c|c|c}
\hline Zone & Inhaled Gas & Perfusion \\
\hline Left lower & 0.32 & 0.81 \\
Left upper & 1.22 & 0.77 \\
Right upper & 1.59 & 1.48 \\
Right lower & 0.99 & 0.97 \\
\hline
\end{tabular}

(B) Fractional Ventilation $(l / \mathrm{min} / \mathrm{l})$ (expected $=3 \cdot 0-5 \cdot 0$ for ventilated lung and $2 \cdot 0-4 \cdot 0$ for perfused lung)

\begin{tabular}{c|c|c}
\hline Zone & Ventilated Lung & Perfused Lung \\
\hline Left lower & $1 \cdot 79$ & $0 \cdot 55$ \\
Left upper & $2 \cdot 63$ & $0 \cdot 57$ \\
Right upper & 3.43 & $0 \cdot 71$ \\
Right lower & 2.97 & 0.61 \\
\hline
\end{tabular}

failure was thought, at this time, to reflect the severity of lung disease, which had been shown to be present as a result of the lung function studies. However, it became clear that congenital heart disease was also present, and a diagnosis of Fallot's tetralogy was confirmed. Finally, the importance of the combined lung and heart disease was recognized, since it was impossible to account for the persistence of the infant's symptoms on 
the basis of his relatively mild degree of heart disease alone.

The exact pathological diagnosis of the lung condition remains speculative at the present time, but presumably it must be characterized by generalized emphysematous changes, causing trapping of gas and maldistribution of ventilation and perfusion within the lung. It may be a variety of congenital lobar emphysema distributed throughout the lungs, possibly like the polyalveolar disease described by Hislop and Reid (1970). The possibility of cystic adenomatoid malformations cannot be excluded, and this has been described previously in association with cardiovascular anomalies such as an aberrant pulmonary blood supply (Hutchin, Friedman and Satltzstein, 1971), but this seems unlikely.

The use of the techniques which have been developed to enable detailed investigation of pulmonary function in the infant are of special interest in this case. Their contribution was very considerable, and little headway could have been made in the interpretation of the problems without their aid. It is not proposed to discuss in detail the theory and practice of these new types of lung function tests in this communication since a fuller account is being prepared, but a few points are worthy of note. The whole-body infant plethysmograph provides a very useful non-invasive tool for measuring lung function in the newborn infant. In order to measure airway resistance with this apparatus, it is essential to avoid the changes in gas temperatures which occur during normal tidal breathing (Radford, 1974). Unfortunately, this has not been done in previous published studies and consequently there are no standards available apart from those which we have prepared in our own laboratory. However, this problem does not apply with respect to the measurement of thoracic gas volume, and extensive data on normal infants now exist. On this basis there can be no doubt that the present patient had very considerable enlargement of the resting lung volume in relation to body weight. When lung volume is abnormally large, it is difficult to calculate the expected values for airways resistance and pulmonary compliance, since these are usually related to the size of the lung volume in normal subjects. His compliance was very low, but this is also difficult to interpret because of the frequency dependence of compliance which would be particularly relevant in this child with gross tachypnoea. Thus conventional total lung function was abnormal but gave no real indication of the pathophysiology.
The results from the simple nitrogen washout $\stackrel{\overline{\bar{N}}}{+}$ measurement of functional residual capacity were abnormal when compared with results that we $\underline{\bar{\sigma}}$ have obtained from normal healthy infants and $\frac{\bar{\omega}}{\vec{D}}$ were very suggestive of poor gas mixing within the $\stackrel{\mathbb{\perp}}{\stackrel{1}{2}}$ lungs. This rebreathing washout study gave an overall estimate of lung function but could notdistinguish localized from generalized disease. It $^{\circ}$ was only possible to make a full analysis of $\vec{\omega}$ regional lung function and thus detect the gen-o eralized nature of the trapped gas and the very $\vec{x}$ poorly ventilated areas by using ${ }^{13} \mathrm{~N}$ and the gamma camera. We know of no adequate data. with which to compare our ${ }^{13} \mathrm{~N}$ studies, because they do not appear to have been carried out in N normal infants. However, the study by Koch $e t$ al. 으 (1973) using ${ }^{133} \mathrm{Xe}$ in normal infants suggests a veryrapid clearance of activity after both injection and $D$ inhalation, although it is difficult to compare theiro results with ours because of the different tech-e niques employed. We have studied one baby with $\overrightarrow{0}$ congenital absence of the right lung and an ap-c parently normal left lung by the same technique. There was no evidence of abnormality in theo single lung, and the washout of activity after both ventilation and injection fell by $90 \%$ in approxi-o mately 0.2 to 0.4 minutes, with a uniform distribution throughout the lung. In the artificially ventilated monkey, Ronchetti et al. (1973) found $\overrightarrow{\vec{O}}$ that the ventilation calculated from the washout 3 compared well with the imposed ventilation. Recent studies in a number of infants with other? conditions of a localized nature have shown very much more effective and even distribution of? ventilation and perfusion to the non-involved regions than was seen in any part of the lung of the present case and give fractional ventilation indices of 3 to $4 \mathrm{~min}^{-1}$.

One problem in the interpretation of the present results concerns the $24 \%$ right-to-left shunt which meant that this proportion of infused radioactivity bypassed the alveoli and was distributed to tissues: throughout the body, including the lung tissuen and thoracic structures within the field of the gamma camera. In fact only a very small proporo tion of this shunted activity would have enteredw the defined fields because the mass of tissue and its blood supply would be only a small proportione (probably under $10 \%$ ) of the mass and blood sup-D ply of the whole body. Thus only some $2.4 \%$ of $^{+}$ infused activity would have entered lung tissue, and calculations show that this would have been? removed over some five minutes. In fact we always correct the lung scan for tissue background $\mathbb{B}$ activity measured continuously over a similato 
area in the camera field, usually over the abdomen. Thus recirculation could not have affected the very slow washout of ${ }^{13} \mathrm{~N}$ seen in the present case (Fig. 3b). It is interesting to note that the mean tissue count in babies without shunts whom we have studied is about $1.6 \%$ of the peak lung count, while that for the present patient was $3 \cdot 1 \%$. This demonstrates that excess shunting was present and, although unlikely to affect the lung scan much, it was worth correcting the curve as we did with the computer.

The technique of regional studies by means of radioisotopic gas which was developed for this infant can provide useful information in selected cases. It requires no collaboration on the part of the patient, and is rapid and simple to perform, although the calculation of the results generally requires computing facilities. The radioactivity administered is generally less than that obtained from simple diagnostic radiology. It would appear to be particularly useful when it is necessary to quantitate the regional extent or severity of a suspected abnormality. From our recent experience this technique is very useful in small children who are too old for the infant plethysmograph and too young for meaningful studies by standard methods.

We wish to express our gratitude to our colleagues from the Department of Medicine, Medical Physics and the Cyclotron Unit for their major contribution to the development and use of the ${ }^{13} \mathrm{~N}$ technique.

\section{REFERENCES}

Chu, J. S., Dawson, P., Klaus, M., and Sweet, A. Y. (1964). Lung compliance and lung volume measured concurrently in normal full-term and premature infants. Pediatrics, 34, 525.

Cook, C. D., Sutherland, J. M., Segal, S., Cherry, R. B., Mead, J., McIlroy, M. B., and Smith C. A. (1957). Studies of respiratory physiology in the newborn infant. III: Measurements of mechanics of respiration. Journal of Clinical Investigation, 36, 440 .

Cross, K. W. (1949). The respiratory rate and ventilation in the newborn baby. Journal of Physiology, $109,459$.

Drorbaugh, J. E., Segal, S., Sutherland, J. M., Oppe, T. E., Cherry, R. B., and Smith, C. A. (1963). Compliance of lung during first week of life. American Journal of Diseases of Children, 105, 63.

Dubois, A. B., Botelho, S. Y., Bedell, G. N., Marshall, R., and Comroe, J. H. (1956). A rapid plethysmographic method for measuring thoracic gas volume. Comparison with nitrogen washout method for measuring functional residual capacity in normal subjects. Journal of Clinical Investigation, 35, 322 .
Geubelle, F., Karlberg, P., Koch, G., Lind, J., Wallgren, G. and Wegelius, C. (1959). L'aération du poumon chez le nouveau-né. Biology of the Neonate, 1, 169.

Heckscher, Th. O., Larsen, O. A., and Lassen, N. A. (1966). Clinical method for determination of regional lung function using intravenous injection of $\mathrm{Xe}^{133}$. Scandinavian Journal of Respiratory Diseases, Supplement 62, p. 31.

Hislop, A. and Reid, L. (1970). New pathological findings in emphysema of childhood, 1. Polyalveolar lobe with emphysema. Thorax, 25, 682.

Howlett, G. (1972). Lung mechanics in normal infants and infants with congenital heart disease. Archives of Disease in Childhood, 47, 707.

Hutchin, P., Friedman, P. J., and Saltzstein, S. L. (1971). Congenital cystic adenomatoid malformation with anomalous blood supply. Journal of Thoracic and Cardiovascular Surgery, 62, 220.

Klaus, M., Tooley, W. H., Weaver, K. H., and Clements, J. A. (1962). Lung volume in the newborn infant. Pediatrics, 30, 111.

Koch, G., Heiskanen, T., Riihimäki, E., Lund, J., Tähti, E., and Österlund, K. (1973). Regional distribution of ventilation and perfusion in the healthy newborn infant and in the idiopathic respiratory distress syndrome. Bulletin de Physiopathologie Respiratoire, 9, 1511.

Krauss, A. N. and Auld, P. A. M. (1970). Measurement of functional residual capacity in distressed neonates by helium rebreathing. Journal of Pediatrics, 77, 228.

Lacourt, G. and Polgar, G. (1974). Development of pulmonary function in late gestation, $I$ : The functional residual capacity of the lung in premature children. Acta Paediatrica Scandinavica, 63,81 .

Lincoln, J. C. R., Stark, J., Subramanian, S., Aberdeen, E., Bonham-Carter, R. E., Berry, C. L., and Waterston, D. J. (i971). Congenital lobar emphysema. Annals of Surgery, 173, 55.

Merenstein, G. B. (1969). Congenital cystic adenomatoid malformation of the lung. American Journal of Diseases of Children, 118, 772.

Nelson, N. M., Prod'hom. L. S., Cherry, R. B., Lipsitz, P. J., and Smit': C. A. (1962). Pulmonary function in the ne' busn infant, 1. Methods: Ventilation and $\mathbb{E}$ :ivuus metabolism. Pediatrics, 30, 963.

function in the rawborn - and (1963). Pulmonary in the normal infant's lung. Journal of Clinical Investigation, 42, 1850.

Phelan, P. D. and Williams, H. E. (1969). Ventilatory studies in healthy infants. Pediatric Research, 3, 425 .

Polgar, G. and String, S. T. (1966). The viscous resistance of the lung tissues in newborn infants. Journal of Pediatrics, 69, 787.

Radford, M. (1974). The measurement of airway resistance and thoracic gas volume in infancy. Archives of Disease in Childhood, 49, 611. 
Roberton, N. R. C., Hallidie-Smith, K. A., and Davis, J. A. (1967). Severe respiratory distress syndrome mimicking cyanotic heart-disease in term-babies. Lancet, 2, 1108.

Ronchetti, R., Benci, S., Federici, E., Manfredi, M., Crofetta, L., and Gentili, G. (1974). Theoretical basis for the calculation of the regional ventilation/ perfusion ratio $(\dot{V} / Q)$ of the lungs in the newborn: Journal of Nuclear Biology and Medicine, 18, 123.

-, Schianchi, G., Manfredi, M., Federici, E., Gentili, G., and Bevilacqua, G. (1973). V/Q distribution in artificially ventilated monkeys studied by inhaled and continuously infused $\mathrm{Xe}^{133}$. Proceedings of Colloquium INSERM on 'Physiologie appliquée de la ventilation assisté chez le nouveau-né', Pont-aMousson (Nancy). Ed. INSERM 129.

Ronchetti, R., Geubelle, F., Chantraine, J. M., and Senterre, J. (1971). Studio del rapporto ventilazione/perfusione nel neonato mediante lo $\mathrm{Xe}^{133}$. Minerva Pediatrica, 23, 1476.

Secker-Walker, R. H., Hill, R. I., Markham, J., Baker, J., Wilhelm, J., Alderson, P. O., and Potchen, E. J. (1973). The measurement of regional ventilation in man: A new method of quantitation. Journal of Nuclear Medicine, 14, 725.

Strang, L. B. (1961). Alveolar gas and anatomical deadspace measurements in normal newborn infants. Clinical Science, 21, 107.

Swyer, P. R., Reiman, R. C., and Wright, J. J. (1960). Ventilation and ventilatory mechanics in the newborn. Journal of Pediatrics, 56, 612.

APPENDIX 1 MEASUREMENT OF LUNG MECHANICS

Studies of lung mechanics were carried out using a specially constructed whole-body infant plethysmograph and applying the techniques described by Dubois et al. (1956). The plethysmograph has been developed by our group (Radford, 1974) and recently modified so that the infant rebreathes oxygen maintained at $37^{\circ} \mathrm{C}$ and fully humidified throughout the measurement. This ensures that all pressure changes within the plethysmograph reflect changes in alveolar pressure and are not invalidated by additional changes due to the heating or cooling of respired gas. In the technique for adults, the subject normally pants in order to minimize such errors, but this is impossible for the infant, who must be allowed to breathe in his normal fashion.

The infant was lightly sedated with chloral hydrate $(30 \mathrm{mg} / \mathrm{kg})$ given immediately before a feed and was studied soon after the feed was completed. He slept quietly within the plethysmograph and was connected to the rebreathing system through a nasal adaptor or a face-mask sealed in place with silicone putty. The infant was initially allowed to breathe quietly for a few breaths while a display of flow plotted against box pressure was watched on the oscilloscope to ensure that they were in phase, thus indicating that the gas was at a uniform temperature throughout the system. The actual temperature was also measured by thermisters placed at strategic points. When sufficiently flat loops were obtained, a record was made on a chart recorder, from which the results were subsequently calculated. The airway was then suddenly occluded at the end of an expiration by inflating a balloon, and a further record was obtained relating plethysmograph pressure to airway pressure. Thoracic gas volume and airway resistance were calculated from these two sets of measurements in the conventional manner. The investigation was repeated two or three times to ensure reproducibility, and allowance was made for the deadspace $(8 \mathrm{ml})$ and resistance $\left(1.5 \mathrm{cmH}_{2} \mathrm{O} / 1\right.$ per sec) of the apparatus when calculating the final results.

Tidal volume, frequency, and ventilation were measured using a pneumotachograph and integrator during free quiet breathing following the of conclusion of the plethysmograph studies. An oesophageal balloon of suitable proportions was passed to mid-oesophagus so that dynamic com-

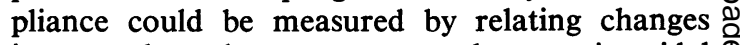
in oesophageal pressure to changes in tidal $\stackrel{\mathbb{Q}}{\mathbb{2}}$ volume. The results of all these studies of lung $\overrightarrow{\vec{B}}$ mechanics in the patient described are given in $\frac{9}{3}$ Table I. The normal values included in this table have been derived from the literature and studies in this laboratory as indicated. The mean expected values which have been calculated have been based on the collected data for a 3-kilogram infant $\underset{x}{\stackrel{2}{\Perp}}$ appropriately weighted for the number of subjects involved in each study.

APPENDIX 2 MEASUREMENT OF FUNCTIONAL RESIDUAL CAPACITY BY REBREATHING

Functional residual capacity was measured by $\mathrm{a}$ rebreathing method which is a modification of the or method described by Krauss and Auld (1970). The N infant rebreathed for about three minutes from N a bag which initially contained a known amount of $\sigma$ pure oxygen $(400 \mathrm{ml}$ in this case). He was connected to the rebreathing bag through a mask sealed in place with silicone putty. Serial samples $\stackrel{\infty}{-}$ of gas were taken from the bag at intervals, after 0 thorough mixing, and analysed for carbon dioxide, oxygen, and argon (which is converted to an equivalent concentration of nitrogen) using a res- $\frac{\pi}{\mathbb{D}}$ piratory mass spectrometer. In order to calculate $\frac{O}{\sigma}$ 
functional residual capacity, it is necessary to know the volume of the system at the time of $\mathrm{N}_{2}$ measurement as this decreases due to continuing oxygen consumption and progressively decreasing carbon dioxide excretion. It is also necessary to correct for the nitrogen removed from the system by sampling during the rebreathing period. A simple digital computer program was written to apply corrections for these various factors in the calculations. The final nitrogen concentration was used in the present case to calculate the functional residual capacity by simple proportions.

With any washout system it is also possible to obtain an equilibrium concentration by a graphical method of solution, in which the difference between the observed gas concentration and the expected equilibrium value is plotted against time on semilogarithmic paper (Ronchetti et al., 1974). Using this technique, it is possible to derive the ultimate equilibrium concentration provided enough data points are available, even if the patient has not reached equilibrium at the end of three minutes. In the present case this was quite easy because of the relatively slow equilibration, so that six points of rising $\mathrm{N}_{2}$ concentration were obtained over the three-minute period. The result of the calculated value for functional residual capacity after a three-minute period of rebreathing and the alternative result calculated by extrapolating to the final equilibrium concentration are both given in Table I. It can be seen that the extrapolated method gives a value which is closer to the thoracic gas volume measured by the purely physical principle of Boyle's Law. In normal children studied in this way, the equilibrium is reached within one minute of rebreathing (personal observations) so that their functional residual capacity is constant when calculated from samples taken at any time after this, providing bag volume is measured at the same time. Serial sampling is, however, desirable, since it demonstrates whether equilibration has been completed, and in the present infant this was clearly not the case even after three minutes of rebreathing.

APPENDIX 3 REGIONAL LUNG FUNCTION MEASURED BY MEANS OF ${ }^{13} \mathrm{~N}$

The regional distribution of lung function was measured using a gamma camera with ${ }^{13} \mathrm{~N}$ as the trace element. This isotope is very insoluble in blood and has a half-life of only 10 minutes. It is particularly suitable for studies of lung function because of its very low blood and tissue solubility but it must be produced by a cyclotron close to where the test is being carried out because of its short half-life.

The technique used for the first study was that developed by Ronchetti et al. $(1971 ; 1973)$ modified for use in the infant. The infant lay supine shortly after a feed, and sedation was unnecessary. A scalp vein needle was inserted just before the procedure to provide a route for injection of the trace isotope. The investigation was carried out in two stages with a perfusion study and an inhalation study. When the infant was sleeping quietly, $0.5 \mathrm{mC}$ of ${ }^{13} \mathrm{~N}$ dissolved in $5 \mathrm{ml}$ of isotonic saline was slowly injected at a constant rate over a oneminute period. The thorax was scanned by the gamma camera throughout the period and over the next five minutes during the subsequent washout of activity by ventilation. After a 20-minute rest the infant was allowed to breathe from a headbox, into which a flow of air labelled with ${ }^{13} \mathrm{~N}$ in a concentration of $0.5 \mathrm{mC}$ per litre was delivered at the rate of 10 litres per minute. The infant breathed the gas for one minute, during which period he inhaled approximately $0.5 \mathrm{mC}$ of activity. The thorax was scanned by the camera during inhalation and for the following five minutes. The data from the gamma camera were processed by an on-line computer so that the activity in any region of the lung corrected for decay with respect to time and for tissue background activity was obtained as a printout. The dose of radioactivity received from the combined injection and inhalation studies was calculated to be of the order of 200 mrads. This dose is comparable to that received during diagnostic radiography.

By the time the second study was performed we had improved and modified the method. We found that the earlier studies did not give enough counts on the camera to be reliable and also that a steady state was almost impossible to achieve. For these and other theoretical reasons the technique was modified so that rapid bolus doses of activity were given into the nasopharynx at the end of expiration and intravenously. Much better definition was obtained. Because the latter part of the earlier type of study was effectively rendered a bolus study by flushing the lines, it was possible to treat both studies in a single mathematical fashion with only a small theoretical error. Regional distribution of blood flow and ventilation was calculated from the regional peak count rate corrected for scanned area (Heckscher, Larsen, and Lassen, 1966), and regional ventilation per unit volume of ventilated or perfused lung was calculated from 
the peak count rate divided by the area under the washout curve (Secker-Walker et al., 1973).

In a normal infant with an alveolar ventilation of $450 \mathrm{ml} / \mathrm{min}$ and a lung volume of $100 \mathrm{ml}$, this ventilation per unit volume for the whole lung should be $4.5 \mathrm{~min}^{-1}$ and in the supine position one would expect this ratio to be evenly distributed throughout the lungs.

Requests for reprints to: Dr. S. Godfrey, Departmente of Paediatrics and Neonatal Medicine, Hammersmith Hospital, Du Cane Road, London W12 0HS. 